\title{
Cognitive Effects of Technology Over Four Years of College
}

\author{
Chad N. Loes \\ Mount Mercy University, \\ Cedar Rapids, IA
}

cloes@mtmercy.edu

\author{
Kem Saichaie \\ University of California, Davis, \\ Davis, CA
}

\begin{abstract}
Technology permeates higher education, yet less is known about the use of established technologies, such as email and other electronic communication mediums (e.g., discussion boards, listservs) for instructional purposes on important student outcomes such as cognitive development. In this study, we use data from the Wabash National Study to estimate the effects of email and other electronic medium use for academic purposes on three measures of cognitive development over four years of college. To investigate this, we regress each measure of cognitive development on email and electronic medium use, while simultaneously controlling for a wide array of potential confounding influences. Net of these influences, we find that email and electronic medium use are positively associated with gains in students' Need for Cognition. These same technologies fail to have more than a chance influence on students' critical thinking skills, however. Lastly, email use is associated with gains in the Positive Attitudes Toward Literacy measure for Whites and females, whereas electronic medium use leads to gains in the same outcome for racial and ethnic minorities. While institutions consider newer technologies for instructional purposes, our findings suggest established technologies can play a powerful role in the development of students' cognitive skills.
\end{abstract}

Keywords: Effective college teaching, pedagogy, technology, cognitive development, critical thinking

\section{Introduction}

The ubiquity of technology in higher education in the twenty-first century is unquestionable (e.g., Allen, Seaman, Lederman, \& Jaschik, 2012). To be sure, $71 \%$ of respondents in recent nationally-representative samples of college students have used freely-available technological course con-

Material published as part of this publication, either on-line or in print, is copyrighted by the Informing Science Institute and Preeminent Leadership and Research Solutions, LLC. Permission to make digital or paper copy of part or all of these works for personal or classroom use is granted without fee provided that the copies are not made or distributed for profit or commercial advantage AND that copies 1) bear this notice in full and 2) give the full citation on the first page. It is permissible to abstract these works so long as credit is given. To copy in all other cases or to republish or to post on a server or to redistribute to lists requires specific permission and payment of a fee. Contact Publisher@InformingScience.org to request redistribution permission. tent (e.g., e-books, e-portfolios) in the course of their studies over the past year, and increasing numbers of students are taking online courses (Dahlstrom, Walker, \& Dziuban, 2013). In fact, US enrollment in fully-online courses increased $21 \%$ from 2009 to 2010 , while on-campus enrollments increased only two percent over the same period (Bates, 2011). As such, it appears that the incorporation of technology into the fabric of higher education has no indication of 
waning. Furthermore, the focus on technology use in colleges is abundantly clear given the federal policy initiatives that promote its inclusion in higher education classrooms (U.S. Department of Education, 2006). Many higher education constituents continue to remain focused on exploring ways to incorporate "new" technology-infused pedagogical approaches (e.g., massively open online courses [MOOCs], flipped, hybrid, and online classes) into the learning process. Despite the emergence of research examining the effects of "new" technology-infused pedagogical approaches on student outcomes, those technologies are far less ubiquitous in the learning process than technologies that are currently more established in collegiate instruction, such as email and other electronic media (e.g., instant messaging, web-based tools) (Dahlstrom et al., 2013). As such, it is critically important researchers and educators continue to investigate and understand the effects of established media on student outcomes.

\section{Literature Review}

Unsurprisingly, a large body of student outcomes research accompanies the substantial increase of technology use in higher education. Within this body of evidence, some individual studies suggest that the use of technology in the learning process does not influence student achievement (e.g., Smeaton \& Keogh, 1999; Taraban \& Rynearson, 1998; Tjaden \& Martin, 1995). We acknowledge the research which opposes the thrust of our investigation positing a relation between technology use and student outcomes; however, a clear preponderance of the evidence suggests students do indeed benefit from technology use. In fact, a number of meta-analyses document the impact of technology on college students' development. For example, using 59 independent evaluations of computer-based college teaching, J. A. Kulik, Kulik, and Cohen (1980) found that computer-based instruction (compared to traditional instruction) was, on average, associated with a .25 standard deviation increase in examination scores. Similarly, in a follow-up meta-analysis of 254 published and unpublished studies, C. L. C. Kulik and Kulik (1991) reported that computer-based instruction raised overall student examination scores by .30 of a standard deviation. Similar advantages were reported more recently by Tamim, Bernard, Borokhovski, Abrami, and Schmid (2011) in their review of over 1,000 technology and student learning studies over the last 40 years.

Although the large corpus of studies documenting the effects of technology on student growth is important, it is essential to note that these meta-analyses focus almost exclusively on student course-level achievement. A nascent body of evidence suggests the influence of technology on students may also extend to broader outcomes theoretically associated with a liberal arts education, such as general cognitive development. Using a sample of over 18,000 undergraduate students at 71 four-year institutions, Kuh and Hu (2001) explored the influence of computer and information technology use on a host of important student outcomes. They found that students benefitted most when they used technology frequently. The use of computers and other information technologies had an overall positive effect on students' self-reported measure of "intellectual development." Similar findings were also reported by Kuh and Vesper (2001) in a study of 125,000 undergraduates from 205 four-year colleges. Specifically, computer use was positively associated with a variety of important self-reported outcomes, including gains in one's ability to think analytically.

The amount of longitudinal research that explores the effects of technology on student outcomes using standardized measures of cognitive development, however, is exceedingly small. In our review of the literature, we uncovered only one study that directly addresses this issue. Using multi-institutional data from the National Study on Student Learning (NSSL), Flowers, Pascarella, and Pierson (2000) explored whether the use of information technology, to wit, using computers or email to communicate with an instructor about course-related matters, influenced scores on standardized measures of reading comprehension, mathematical reasoning, critical thinking, or a 
composite measure of all three dimensions of cognitive development. Neither computer nor email use had a statistically reliable effect on any measure of cognitive development among those attending four-year institutions. For students at two-year colleges, however, computer use had a positive effect on reading comprehension and the composite cognitive development measure. Surprisingly, email use had a significant negative effect on all four outcome measures. Lastly, a number of conditional effects were uncovered by race. Specifically, computer use was associated with gains in reading comprehension for Black students, whereas email use negatively influenced reading comprehension among Hispanics - suggesting the influence of technology use on cognitive outcomes might be conditional on student race/ethnicity.

The current investigation extends what is known about the relation between information technology use and overall cognitive development during college in at least five ways. First, in our review of the literature, we did not uncover any research that explores the influence of technology on cognitive outcomes over four years of college; most investigations on this topic focus only on the first year of college. Second, in contrast to nearly all of the research on the impact of technology on intellectual development, we also use a standardized instrument to measure critical thinking. Although it is sometimes practically necessary to use self-reported measures of intellectual development, standardized instruments that assess critical thinking are generally viewed as more psychometrically valid measures (Bowman, 2010; Pascarella, 2001; Pike, 1996). Third, in contrast to Flowers and his colleagues (2000), we explore somewhat different dimensions of cognitive development among a very different sample of undergraduates over four years of college. Given the profound changes in students' exposure to and advancement of technology since the Flowers et al. (2000) data were collected approximately 20 years ago, we believe it is reasonable to expect the effects of technology on cognitive development might not hold indefinitely. However, this issue has yet to be investigated.

Fourth, we also control for students' tested precollege academic ability. The inclusion of a pretest for academic ability is a particularly important point, as gains in cognitive development as a result of exposure to information technology found in prior research could simply be an artifact of differing levels of academic ability. Lastly, we include a statistical procedure to adjust for the non-random nature of the data (discussed in greater detail later in this paper).

Given the research outlined above, we hypothesize that email and other technology use for instructional purposes during college will have an overall net positive effect on each of our measures of cognitive development. Moreover, considering the dramatic demographic changes among students (e.g., by race and ethnicity) since the data were collected in 1992 for the Flowers

et al. (2000) study, we predict that some of these effects will be moderated by student background characteristics (Pascarella, 2006; U.S. Department of Education, 2008). To be clear, we acknowledge that newer, more emergent technologies (e.g., blogs, social media, virtual reality) are gaining ground in higher education. However, given the modicum of studies focusing on the role more established and more frequently-used instructional technologies (such as email and electronic media) on student outcomes, it is important to not overlook the potential role they play in students' cognitive development.

\section{Theoretical Framework}

In this study, we draw upon constructivist theory, which was developed in the 1970s (Vygotsky, 1978) and applied to other studies examining the role of technology on cognitive development (e.g., Chickering \& Erhmann, 1996; Huang, 2002; Jonassen, 1999; Jonassen, Howland, Moore, \& Marra, 2002). Generally, constructivism suggests that students expand upon prior experiences and knowledge through exposure to new materials and by attempting to make new connections to prior knowledge by "building, shaping, and configuring meaning" (Cain \& Pitre, 2008, p. 32). Cain and Pitre applied a constructivist lens to information technology and posit that it supports how 
students interact with instructors, peers, and information. Furthermore, they suggest that information technology allows students the opportunity to access a wealth of content quickly. Students must process the information cognitively to build upon prior knowledge through the affordances of technology, such as rapidly accessing multiple data points from a number of sources. They conclude that information technology functions as an important lever whereby students can exchange information in the process of forming new knowledge.

\section{Research Methods}

\section{Samples and Data Collection}

The data used for this study came from the Wabash National Study of Liberal Arts Education (WNSLAE). The WNSLAE is a large-scale, longitudinal study that investigates factors associated with important outcomes theoretically associated with a liberal arts education. Over 60 colleges and universities responded to a national invitation to participate in the WNSLAE. A purposive sample was drawn from the group of institutions that applied to be a part of the WNSLAE. These institutions were selected in an effort to diversify the institutional sample to include various geographic regions, institutional sizes, and student demographics. These institutions also varied in terms of academic selectivity and undergraduate enrollment. Because the study is principally focused on the effects of liberal arts education, liberal arts institutions were purposefully overrepresented. Of the 17 institutions included in the sample, three are considered research universities, three are regional universities (non-doctoral granting), and 11 are liberal arts colleges. All of the liberal arts colleges and one of the research universities are private, while the remaining research and regional universities are considered public institutions.

The first panel of data was collected from 4,193 students at 17 institutions in the fall of 2006 . During this phase of the data collection, a precollege survey was distributed to obtain information on student demographic characteristics, family background, high school experiences, political preferences, educational degree plans, etc. Additionally, respondents also completed a battery of surveys that captured a host of intellectual and personal development measures theoretically associated with a liberal arts education. One of these surveys was the critical thinking module of the Collegiate Assessment of Academic Proficiency (CAAP). Due to the extensive amount of time required to complete the critical thinking module of the CAAP, half of the sample was randomly selected to complete this instrument during the initial data collection. The other random half of the sample completed another instrument, the Defining Issues Test, of approximately equal length. Unlike the critical thinking module of the CAAP, the Need for Cognition (NFC) and Positive Attitude Toward Literacy (PATL) measures (described in detail later in this paper) were administered to all respondents.

The follow-up data collection was conducted during the spring 2010 term. This data collection took about two hours, and participating students were paid an additional stipend of \$50 each. Two types of data were collected. The first was based on questionnaire instruments that collected extensive information on students' experience of college. Two complementary instruments were used: the National Survey of Student Engagement (NSSE) (Kuh, 2001) and the WNSLAE Student Experiences Survey (WSES). These instruments were designed to capture student involvement in a broad variety of different activities during college (e.g., coursework, clubs, study habits, interactions with other students, involvement in cultural/social activities, and the like). The second type of data collected consisted of follow-up (or posttest) measures of instruments measuring dimensions of intellectual and personal development, including the CAAP critical thinking test, and NFC and PATL measures that were first completed in the initial data collection. All students completed the NSSE and WSES prior to completing the follow-up instruments assessing intellec- 
tual and personal development. Both the initial and follow-up data collections were administered and conducted by ACT (formerly the American College Testing Program).

Of the original 4,193 respondents in the first data collection, 2,212 participated in the spring 2010 follow-up data collection, representing a response rate of 52.8\%. Of these 2,212 students, we had useable data on 1,002 respondents for the critical thinking outcome (as noted earlier, the critical thinking module of the CAAP was randomly assigned to only half the sample). We also had useable data for 2,086 respondents on the NFC measure, and 2,090 for the PATL outcome.

\section{Variables}

We used three dependent variables in this study that have been conceptualized elsewhere as dimensions of cognitive development (e.g., Laird Nelson, Seifert, Pascarella, Mayhew, \& Blaich, 2014; Martin \& Seifert, 2011). The first dependent variable we examined is end of fourth-year critical thinking. We assessed end of fourth-year critical thinking by using scores from the Collegiate Assessment of Academic Proficiency (CAAP) developed by the American College Testing Program (ACT). The critical thinking test is a 40-minute, 32-item instrument designed to measure a student's ability to clarify, analyze, evaluate, and extend arguments. The test requires students to read several passages that are commonly found in college curricula and then select a multiplechoice answer that supports best a general conclusion about the series of arguments presented in the passage. The critical thinking module of the CAAP is divided into three sections: analysis of elements of an argument, evaluation of an argument, and extension of an argument. The internal consistency reliability of the CAAP ranges between .81 (Spearman-Brown) and .85 (KuderRichardson) among multiple populations of college freshmen (ACT, 2011). The CAAP critical thinking module correlates .75 with the multiple-choice Watson-Glaser Critical Thinking Appraisal (Pascarella, Bohr, Nora, \& Terenzini, 1995) and .58 with the written Collegiate Learning Assessment (Klein, Liu, \& Sconing, 2009).

Our second dependent variable — end of fourth-year NFC — is a measure of an individual's inclination to inquire and engage in effortful cognitive activities. On one hand, individuals who score high on the NFC scale are more likely to "seek, acquire, think about, reflect back on information to make sense of stimuli, relationships, and events in their world" (Cacioppo, Petty, Feinstein, \& Jarvis, 1996, p. 198). Individuals who score low on the NFC scale, on the other hand, are likely to rely on other individuals to make sense of their surroundings. As it relates to college student growth, NFC is positively associated with high levels of verbal ability, generating complex attributions for human behavior, desire to maximize information gained over maintaining one's perceived reality (Cacioppo, et al., 1996), and college grades (Elias \& Loomis, 2002). The reliability of the NFC scale ranges from .83 to .91 in samples of college students (Cacioppo, Petty, \& Kao, 1984).

The final dependent variable - end of fourth-year PATL — is a measure of the extent to which an individual personally enjoys literacy activities, such as reading literature, poetry, scientific texts, and/or historical material, and expressing his or her ideas through writing (Bray, Pascarella, \& Pierson, 2004). The PATL scale is positively correlated with reading unassigned books, reading comprehension, and library use within college student samples. The reliability of the PATL scale ranges from .70 to .72 in samples of college students (Bray et al., 2004; Loes, Salisbury, \& Pascarella, 2013).

The independent variables in this study consist of two single-item measures that capture technology use. First, we assessed the extent to which respondents use email to communicate with instructors during their time in college (hereinafter email). Next, we evaluated the degree to which students use technology in discussing or completing assignments (hereinafter electronic medium). In particular, students were presented with the following questions: During the current school 
year, how often have you used email to communicate with an instructor?" and "During the current school year, how often have you used an electronic medium (listserv, chat group, Internet, instant messaging, etc.) to discuss or complete an assignment?" Response options are: $4=$ "very often"; 3 = "often"; 2 = "sometimes"; 1 = "never."

\section{Guiding Conceptual Model and Control Variables}

Several conceptual models were utilized in our attempt to understand the influence of technology and the collegiate experience on students (e.g., Astin, 1993; Pascarella, 1985; Pascarella \& Terenzini, 1991, 2005). Overall, these models suggest at least four sources of influence need to be accounted for when assessing the impact of college on students, to wit, student background characteristics, institutional type, and academic and social experiences during college. To that end, we created fully-specified models to estimate the impact of technology use on cognitive outcomes over four years of college. In particular, we included controls for student background characteristics (tested precollege ACT or equivalent score, race, sex, precollege academic motivation), institutional type, academic experiences (academic major, and the extent to which the respondent was exposed to clear and organized instruction), and social experiences during college (total hours worked on/off campus, and whether the respondent lived in campus housing). Detailed operational definitions for all predictor and outcome variables (including parallel pretest measures) are shown in Table 1.

\section{Table 1. Variable definitions}

Variable Name

Email use

Electronic Medium Use

End of Fourth-year Critical

Thinking (Spring 2010)

Precollege Critical Thinking (Fall 2006)

End of Fourth-year Need For Cognition (Spring 2010)

Precollege Need For Cognition Scale (Fall 2006)
Operational Definition

The extent to which the respondent used email to communicate with an instructor (Coded: 5 = "very often"; 4 = "often"; 3 = "sometimes"; 2 = "rarely"; 1 = "never.")

The extent to which the respondent used an electronic medium (listserv, chat group, Internet, instant messaging, etc.) to discuss or complete an assignment (Coded: $5=$ "very often"; 4 = "often"; 3 = "sometimes"; 2 = "rarely"; $1=$ "never.")

A student's end of fourth-year score on the CAAP critical thinking module

A student's precollege score on the critical thinking module of the Collegiate Assessment of Academic Proficiency (CAAP)

A student's end of fourth-year score on the Need for Cognition measure

An 18-item scale (internal consistency reliability $=0.90$ ) that asks participants to respond to the following:

1. I would prefer complex to simple problems.

2. I like to have the responsibility of handling a situation that requires a lot of thinking.

3. Thinking is not my idea of fun.

4. I would rather do something that requires little thought than something that is sure to challenge my thinking abilities.

5. I try to anticipate and avoid situations where there is 
End of Fourth-year Attitude

Toward Literacy (Spring 2010)

Precollege Attitude Toward Literacy Scale (Fall 2006)

likely a chance I will have to think in depth about something.

6. I find satisfaction in deliberating hard and for long hours.

7. I only think as hard as I have to.

8. I prefer to think about small, daily projects to longterm ones.

9. I like tasks that require little thought once I've learned them.

10. The idea of relying on thought to make my way to the top appeals to me.

11. I really enjoy a task that involves coming up with new solutions to problems.

12. Learning new ways to think doesn't excite me very much.

13. I prefer my life to be filled with puzzles that I must solve.

14. The notion of thinking abstractly is appealing to me.

15. I would prefer a task that is intellectual, difficult, and important to one that is somewhat important but does not require much thought.

16. I feel relief rather than satisfaction after completing a task that required a lot of mental effort.

17. It's enough for me that something gets the job done; I don't care how or why it works.

18. I usually end up deliberating about issues even when they do not affect me personally.

A student's end of fourth-year score on the Attitude Toward Literacy measure

A six-item scale (internal consistency reliability $=0.71$ ) which includes the following:

1. I enjoy reading about history.

2. I enjoy reading poetry and literature.

3. I enjoy reading about science.

4. I enjoy expressing my ideas in writing.

5. If I have something good to read, I am never bored.

6. After writing about something, I see that subject differently.

\section{Analyses}

We carried out our analyses in two stages. In stage one, we created separate models for each dependent variable, where we regressed each outcome on the email and electronic medium independent variables, as well as all the control measures described earlier (e.g., ACT or equivalent score, race, sex, precollege academic motivation, institutional type, academic major, the extent to which the respondent was exposed to clear and organized instruction, total hours worked on/off campus, and whether the respondent lived in campus housing). 
In stage two, we sought to determine whether the influence of email and electronic medium use is conditional based on student race, pretested academic ability, or sex. To accomplish this, we created cross-product terms between race, pretested academic ability, sex, on the one hand, and email and electronic medium use on the other (Flowers et al., 2000). We then separately added each cross-product to the general effects equation. A statistically significant increase in the explained variance $\left(\mathrm{R}^{2}\right)$ would indicate the presence of conditional effects, which could then be further explored (Pedhazur, 1982). In both stages of the analyses, we continued to use regression procedures that adjusted the standard errors to account for the nested nature of the data (described below). All of our analyses are appropriately weighted and adjusted to the actual sample size for correct standard errors in significance tests.

The data used in this study were obtained from 17 institutions that differ in a number of important ways (e.g., selectivity, size). Because of these differences, it was necessary for us to account for the nesting or "clustering" effect that occurs in such designs. Clustering is a concern because students within each institution are more likely to be similar to one another than students at other institutions. In other words, in terms of college impacts, there are more within-institution differences than between-institution differences (Pascarella \& Terenzini, 1991, 2005). If we decided against accounting for the clustering effect in our regression procedures, our error terms in the models would be correlated. Accordingly, our estimates would produce artificially reduced standard errors, which violates one of the assumptions of Ordinary Least Squares regression, and thus results in an increased possibility of committing Type I error (Ethington, 1997; Raudenbush \& Bryk, 2001).

To address this problem, we used the svy option in Stata, the statistical program we used to analyze our data. The use of the svy statistical routine adjusts the standard errors to account for the clustering issue (Groves et al., 2004). Because we used multi-institutional data in this study, it may be argued that we should have used hierarchical linear modeling (HLM) as our primary analytical approach. Two issues weighed against this technique, however. First, the literature on the use of HLM clearly suggests 17 aggregates are too few to generate adequate statistical power for between-institution variables. Further, our focus was at the individual - not institutional-level of analysis. As such, we chose against using HLM in our analyses (Ethington, 1997; Raudenbush \& Bryk, 2001).

It is important to note that in addition to the controls for clustering and a wide-range of potential confounders, we also included parallel pretest/posttest measures. As a result of these very conservative prediction models, we expected to find what appear to be relatively small coefficients. Given the fully-specified nature of our equations, we considered any significant relations particularly important. Finally, our inclusion of a pretest measure for each outcome is a very important point, as the pretest-posttest research design is one of the most effective ways to control for selection bias (Astin \& Lee, 2003; Pascarella, 2006).

\section{Results}

Descriptive statistics for all variables used in this study are located in Table 2. The averages for email and electronic medium use ranged from 2.98 to 3.58 on a four-point scale. We examined all the variables in our models for potential issues of multicollinearity by conducting a variance inflation factor test. None of the variance inflation factors in any of our models exceeded 2.30, suggesting the multicollinearity of the variables is well within an acceptable range (Belsley, Kuh, \& Welsch, 1980; Cohen, Cohen, West, \& Aiken, 2003; Marquardt, 1970; Myers, 1990). 


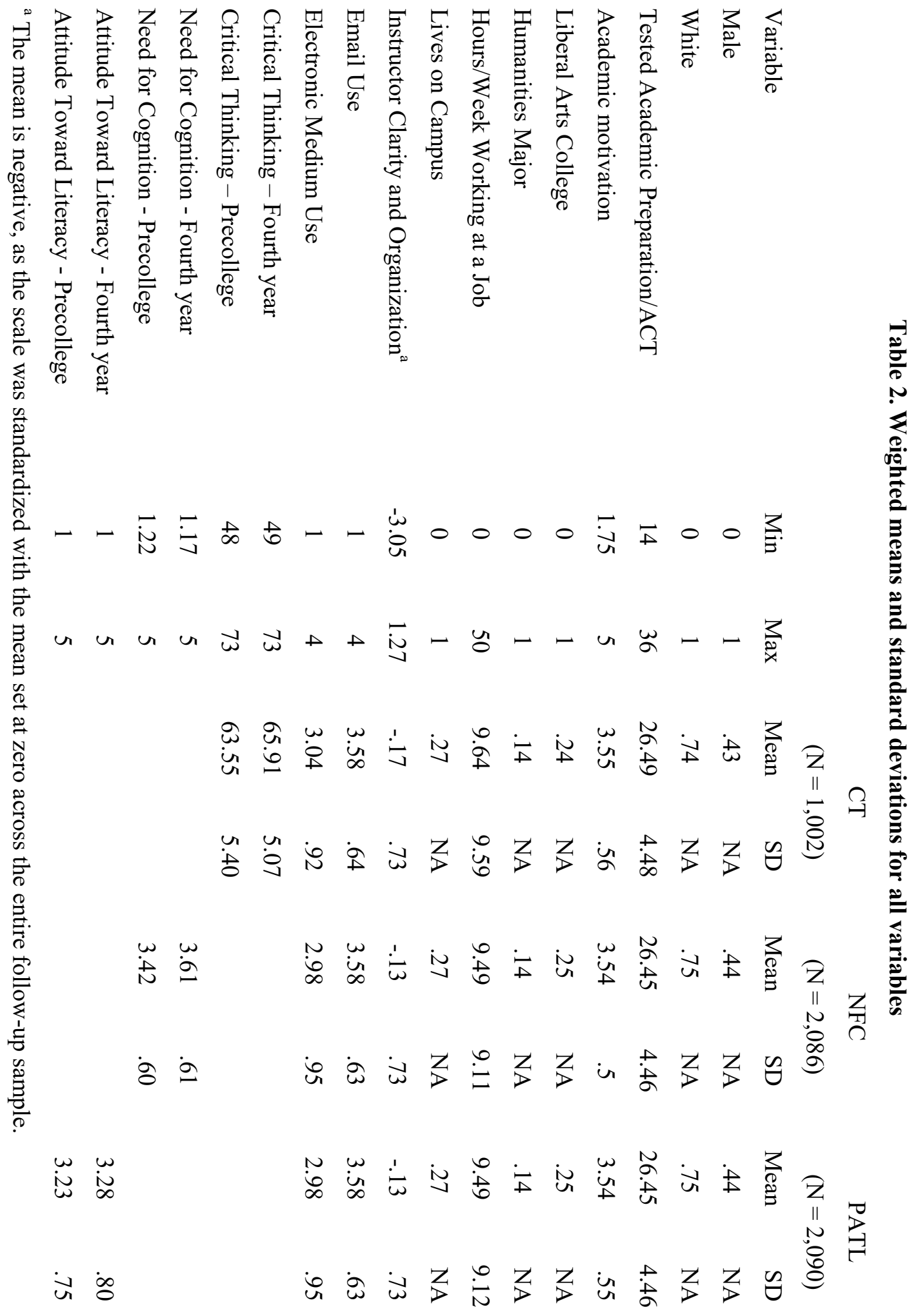


Table 3 includes the OLS regression results for each outcome measure. First, it is worthy to note that all the predictor variables in the model explained a substantial amount of the shared variance $\left(\mathrm{R}^{2}=.62\right)$ in the critical thinking outcome, as well as the NFC and PATL measures $\left(\mathrm{R}^{2}=.41\right)$. Neither email use $(b=-.05, p>.05)$ nor electronic medium use $(b=.04, p>.05)$ had more than a chance effect on end of fourth-year critical thinking. Exposure to both of these technologies led to gains in students' NFC, however. Specifically, email use was positively associated with gains in this outcome $(b=.10, p<.05)$, as was electronic medium use $(b=.05, p<.01)$. The use of email $(b=.04, p>.05)$ and electronic media $(b=-.02, p>.05)$ failed to significantly influence PATL, however.

The results of our conditional effect analyses are also displayed in Table 3. Although we did not uncover any conditional effects for the critical thinking or NFC outcomes, a number of significant conditional effects emerged for the PATL measure. Specifically, we found that email use was positively associated with gains in PATL for Whites $(b=.08, p<.05)$ and females $(b=.13, p<$ $.01)$, whereas electronic medium use led to gains in PATL for racial and ethnic minorities $(\mathrm{b}=$ $.09, \mathrm{p}<.05)$. Lastly, it is important to note that because we included a parallel pretest measure of each outcome variable, we are stating that students who utilized email or electronic media accrued actual gains in those outcome measures. This has been empirically demonstrated elsewhere (see, Pascarella, Wolniak, \& Pierson, 2003).

\section{Table 3. Estimated general and conditional effects of technology use on cognitive outcomes over four years of college ${ }^{a}$}

\begin{tabular}{lcccc} 
& \multicolumn{2}{c}{ Email Use } & \multicolumn{2}{c}{ Electronic Medium Use } \\
Dependent Variable & $\mathrm{b}$ & $\mathrm{SE}$ & $\mathrm{b}$ & $\mathrm{SE}$ \\
Critical Thinking $^{\mathrm{b}}$ & -0.05 & 0.08 & 0.04 & 0.04 \\
Need for Cognition $^{\mathrm{c}}$ & $0.10^{*}$ & 0.03 & $0.05^{* *}$ & 0.02 \\
Positive Attitude Toward Literacy $^{\mathrm{c}}$ & 0.04 & 0.03 & -0.02 & 0.04 \\
Whites $^{\mathrm{d}}$ & $0.08^{*}$ & 0.03 & -0.05 & 0.04 \\
Racial/Ethnic Minorities $^{\mathrm{d}}$ & -0.08 & 0.05 & $0.09 *$ & 0.04 \\
Males $^{\mathrm{e}}$ & -0.04 & 0.03 & -0.01 & 0.03 \\
Females $^{\mathrm{e}}$ & $0.13^{* *}$ & 0.04 & -0.03 & 0.05 \\
$* \mathrm{p}<.05 .{ }^{* *} \mathrm{p}<.01 . * * * \mathrm{p}<.001$ & & & &
\end{tabular}

${ }^{a}$ Also includes controls for: sex, race, tested academic preparation/act score, precollege academic motivation, precollege measures for each outcome, institutional type, humanities major, hours/week working at a job, living on campus, and instructor clarity/organization.

${ }^{\mathrm{b}} \mathrm{R}^{2}=.62$

${ }^{\mathrm{c}} \mathrm{R}^{2}=.41$

${ }^{\mathrm{d}, \mathrm{e}}$ Positive Attitude Toward Literacy subsample conditional effects are significantly different from one another at $\mathrm{p}<.05$

\section{Summary, Discussion, and Limitations}

This paper explored the relation between information technology use and overall cognitive development during college. Interestingly, even though information technology is commonplace in 
every institution of higher education, less is known about its influence on the cognitive development of undergraduate students. The findings presented here take a step toward understanding better the role technology plays in the development of students' general cognitive skills in several ways.

It appears the use of technologies that are more established in higher education, such as email (to communicate with an instructor), and electronic medium use to discuss or complete an assignment is associated with gains in important student outcomes theoretically associated with a liberal arts education. More specifically, the use of email and electronic media for instructional purposes is positively associated with gains in students' NFC, but not their critical thinking skills. Email use is associated with gains in PATL for Whites and females, whereas electronic medium use is associated with gains in the same outcome for racial and ethnic minorities.

It is interesting that students' use of email and electronic media were significant predictors of NFC gains in the general effects model, but not for critical thinking or PATL. It is possible that this might be due to hesitancy on the part of faculty in using technology in the teaching and learning process. In fact, Sorcinelli, Austin, Eddy, and Beach (2006) report that incorporating technology into instruction remains a primary concern for postsecondary faculty. While adoption and inclusion of technology may be an area of trepidation, Zhu and Kaplan (2014) note that many institutions have invested and articulated the roles of faculty development units (i.e., centers for teaching and learning) and instructional technologists to focus on the implementation of technology in the classroom for academic purposes.

Although the use of technology has been linked to gains in "intellectual development" (Kuh \& $\mathrm{Hu}, 2001$ ), it failed to have more than a chance influence on the measure of critical thinking used in our study. As we noted earlier, scholars suggest standardized measures of critical thinking are more psychometrically valid than self-reported estimates (Bowman, 2010; Pascarella, 2001). As such, previous research may simply be masking the chance influence of technology on cognitive growth (i.e., committing Type I error). As a result, our findings underscore the importance of appropriately measuring such an important and complex construct.

The NFC general effects findings have particularly salient implications for pedagogical practice. In particular, the use of email and electronic media in college instruction led to gains in NFC for all students regardless of individual background characteristics. Given that nearly all campuses have email and other electronic media (e.g., learning management systems, listserv, chat tools, Internet, a/synchronous messaging) at their disposal, use of these technologies in the teaching and learning process is a relatively efficient and inexpensive way to increase students' proclivity to engage in effortful cognitive activities. This finding is especially timely, given recent criticism of student learning and engagement in higher education (e.g., Arum \& Roksa, 2011). Finally, the inclusion of a covariate to control for tested academic preparation/ACT score allowed us to understand better the changes in cognitive development as a result of exposure to information technology that has been uncovered in other research (e.g., Flowers et al., 2000) which could simply have been an artifact of differing levels of academic ability in those prior investigations.

These findings are a step toward understanding better the role of technology in student growth at the postsecondary level. Ultimately, cognitive development as a result of technology relies on how effectively instructors align technological interventions with learning outcomes and the nature of the technological integrations into the course curriculum (Chickering \& Ehrmann, 1996). For example, researchers have found that pairing active learning pedagogical methods and the integration of technology tools, such as personal response systems (clickers), can lead to increases in measures of student achievement (Deslauriers, Schelew, \& Wieman, 2011). Many course and learning management systems have tools to facilitate electronic means of self-reflection (Brescia \& Miller, 2006), as do third-party software sites such as Wordpress. 
Bowen (2012) promulgated a number of strategies to engage students via email, to promote passion for the subject matter, and provide an initial exposure to course content. Bowen also provides a number of ways to engage students with information technology and points out that multimedia resources such as MERLOT (www.merlot.org), Open Educational Resources (www.oercommons.org), and TED-ED (ed.ted.com) are freely-available to instructors to incorporate into their courses. As institutions continue to invest in technology, and the proliferation of technological devices accelerates, Kuhlenschmidt (2010) suggests that faculty, support staff, and technologists should incorporate thoughtful assessment of the types of technological tools instructors select for pedagogical purpose and rigorously measure their effectiveness.

Constructivist theory suggests that technology has important implications beyond the simple cognitive tasks of processing, retrieving, and storing of information (Cain \& Pitre, 2008). Our findings demonstrate that relations exist between the use of informational technology and the development of some general cognitive skills. The incorporation of technology is merely one intervention to help develop students' cognitive skills. Limited research exists on the impact of technology on cognitive development during college - especially with regard to longitudinal, multiinstitutional investigations over four years of college. Our results provide postsecondary institutions with additional evidence to consider thoughtfully the importance of role of information technology over the course of a four-year undergraduate experience.

Although this study provides additional insight into the relation between technology use and cognitive development during college, it is not without limitations. First, our measures of technology are by no means completely inclusive of all technologies that are employed in the teaching and learning process. In fact, using email to communicate with an instructor, and use of other electronic media to discuss or complete an assignment might be viewed as not completely encompassing of "technology" in the 21 st century. Moreover, given newer technologies used in the college classroom today (e.g., clickers, virtual reality), it could be argued that the effect of those technologies is more relevant than the measures we explored in this study. However, a recent study of technology use among US faculty reveals a relatively slow adoption of newer technologies into the teaching and learning process. For example, only $12 \%$ of faculty respondents use "clickers" to obtain student responses, and a mere 15\% use Skype or video to encourage class or real time interactions (McGoldrick, Watts, \& Economou, 2015). In contrast, current research suggests that email and electronic media use in the teaching and learning process are far more ubiquitous than other "new" technologies (Dahlstrom et al., 2013). Although email use was more commonly used among the respondents in our sample, both technologies were used rather frequently by those in the sample (use ranges from 2.98 to 3.58 on a four-point scale). As such, we argue that understanding the effects of these oft-used technologies remains especially salient.

In conclusion, our results provide postsecondary institutions with additional evidence on the role of information technology in undergraduate education. Collectively, our findings provide faculty and administrators with instructional strategies that are relatively inexpensive and easy to implement in the teaching and learning process. Furthermore, these instructional approaches appear to enhance dimensions of cognitive development that are theoretically associated with a liberal arts education. As researchers continue to investigate the cognitive impacts of newer technologies, our findings underscore the importance of continuing to explore established technologies that remain ubiquitous on college campuses throughout the US. Continuing to incorporate these technologies into collegiate instruction will help foster important outcomes that are championed at perhaps every institution of higher education. 


\section{Acknowledgements}

This research is supported by a grant from the Center of Inquiry in the Liberal Arts at Wabash College to the Center for Research on Undergraduate Education at The University of Iowa. Corresponding author is Chad Loes. He may be reached at cloes@mtmercy.edu

\section{References}

Allen, I. E., Seaman, J., Lederman, D., \& Jaschik, S. (2012). Digital faculty: Professors, teaching and technology, 2012. Retrieved December 1, 2015 from https://www.insidehighered.com/news/survey/digital-faculty-professors-and-technology-2012

American College Testing Program (ACT). (2011). CAAP technical handbook 2011-2012. Available from http://www.act.org/caap/pdf/CAAPTechnicalHandbook.pdf

Arum, R., \& Roksa, J. (2010). Academically adrift: Limited learning on college campuses. Chicago, IL: University of Chicago Press. doi:10.7208/chicago/9780226028576.001.0001

Astin, A. W. (1993). What matters in college? Four critical years revisited. San Francisco, CA: JosseyBass.

Astin, A. W., \& Lee, J. J. (2003). How risky are one-shot cross-sectional assessments of undergraduate students? Research in Higher Education, 44(6), 657-672. doi:10.1023/A:1026175525173

Bates, A. W. (2011). 2011 outlook for online learning and distance education. Ontario, Canada: Contact North, Sudbury.

Belsley, D. A., Kuh, E. \& Welsch, R. E. (1980). Regression diagnostics: Identifying influential data and sources of collinearity. New York, NY: John Wiley. doi:10.1002/0471725153

Bowen, J. A. (2012). Teaching naked: How moving technology out of your college classroom will improve student learning. New York, NY: John Wiley \& Sons.

Bowman, N. A. (2010). Can 1st-year college students accurately report their learning and development? American Educational Research Journal, 47(2), 466-496. doi:10.3102/0002831209353595

Bray, G. B., Pascarella, E., \& Pierson, C. (2004). Postsecondary education and some dimensions of literacy development: An exploration of longitudinal evidence. Reading Research Quarterly, 39(3), 306-330. doi:10.1598/RRQ.39.3.3

Brescia, W., \& Miller, M. T. (2006). What's it worth? The perceived benefits of instructional blogging. Electronic Journal for the Integration of Technology in Education, 5(1), 44-52.

Cacioppo, J. T., Petty, R. E., Feinstein, J. A., \& Jarvis, W. B. G. (1996). Dispositional differences in cognitive motivation: The life and times of individuals varying in need for cognition. Psychological Bulletin, 119(2), 197-253. doi:10.1037/0033-2909.119.2.197

Cacioppo, J. T., Petty, R. E., \& Kao, C. F. (1984). The efficient assessment of need for cognition. Journal of Personality Assessment, 48(3), 306-307. doi:10.1207/s15327752jpa4803_13

Cain, D. L., \& Pitre, P. E. (2008). The effect of computer mediated conferencing and computer assisted instruction on student learning outcomes. Journal of Asynchronous Learning Networks, 12, 31-52.

Chickering, A. W., \& Ehrmann, S. C. (1996). Implementing the seven principles: Technology as lever. American Association for Higher Education and Accreditation Bulletin, 49, 3-6.

Cohen, J., Cohen, P., West, S. G., \& Aiken, L. S. (2003). Applied multiple regression/correlation analysis for the behavioral sciences. Mahwah, NJ: L. Erlbaum Associates.

Dahlstrom, E., Walker, J.D., \& Dziuban, C. (2013). ECAR Study of Undergraduate Students and Information Technology. Louisville, CO: EDUCAUSE Center for Analysis and Research.

Deslauriers, L., Schelew, E., \& Wieman, C. (2011). Improved learning in a large-enrollment physics class. Science, 332(6031), 862-864. 
Elias, S., \& Loomis, R. (2002). Utilizing need for cognition and perceived self-efficacy to predict academic performance. Journal of Applied Social Psychology, 32(8), 1687-1717. doi:10.1111/j.15591816.2002.tb02770.x

Ethington, C. A. (1997). A hierarchical linear modeling approach to studying college effects. In J. C. Smart (Ed.), Higher education: Handbook of theory and research, Volume XII (pp. 165-194). New York: Agathon Press.

Flowers, L., Pascarella, E. T., \& Pierson, C. T. (2000). Information technology use and cognitive outcomes in the first year of college. Journal of Higher Education, 71(6), 637-667. doi:10.2307/2649157

Groves, R., Fowler, F., Couper, M., Lepkowski, J., Singer, E., \& Tourangeau, R. (2004). Survey methodology. Hoboken, NJ: Wiley-Interscience.

Huang, H. M. (2002). Toward constructivism for adult learners in online learning environments. British Journal of Educational Technology, 33(1), 27-37. doi:10.1111/1467-8535.00236

Jonassen, D. H. (1999). Designing constructivist learning environments. Instructional design theories and models: A new paradigm of instructional theory, 2, 215-239.

Jonassen, D. H., Howland, J., Moore, J., \& Marra, R. M. (2002). Learning to solve problems with technology: A constructivist perspective. Columbus, $\mathrm{OH}$ : Merrill/Prentice Hall.

Klein, S., Liu, O., \& Sconing, J. (2009). Test validity study (TVS) report. Washington, DC: Fund for the Improvement of Postsecondary Education.

Kuh, G. D. (2001). The national survey of student engagement: Conceptual framework and overview of psychometric properties. Bloomington, IN: Indiana University, Center for Postsecondary Research.

Kuh, G. D., \& Hu, S. (2001). The relationships between computer and information technology use, selected learning and personal development outcomes, and other college experiences. Journal of College Student Development, 42(3), 217-232.

Kuh, G. D., \& Vesper, N. (2001). Do computers enhance or detract from student learning? Research in Higher Education, 42(1), 87-102. doi:10.1023/A:1018768612002

Kuhlenschmidt, S. (2010). Issues in technology and faculty development. In K. J. Gillespie, D. L. Robertson, \& Associates (Eds.), A guide to faculty development (2nd ed.). San Francisco, CA: JosseyBass.

Kulik, C. L. C., \& Kulik, J. A. (1991). Effectiveness of computer-based instruction: An updated analysis. Computers in Human Behavior, 7(1), 75-94.

Kulik, J. A., Kulik, C. L. C., \& Cohen, P. A. (1980). Effectiveness of computer-based college teaching: A meta-analysis of findings. Review of Educational Research, 50(4), 525-544. doi:10.1016/07475632(91)90030-5

Laird Nelson, T. F., Seifert, T. A., Pascarella, E. T., Mayhew, M. J., \& Blaich, C. F. (2014). Deeply affecting first-year students' thinking: Deep approaches to learning and three dimensions of cognitive development. The Journal of Higher Education, 85(3), 402-432. doi:10.1353/jhe.2014.0017

Loes, C. N., Salisbury, M. H., \& Pascarella, E. T. (2013). Diversity experiences and attitudes toward literacy: Is there a link? The Journal of Higher Education, 84(6), 834-865. doi:10.1353/jhe.2013.0039

Marquardt, D.W. (1970). Generalized inverses, ridge regression and biased linear estimation. Technometrics, 12(3), 591-612. doi:10.2307/1267205

Martin, G. L., \& Seifert, T. A. (2011). The relationship between students' interactions with student affairs professionals and cognitive outcomes in the first year of college. Journal of Student Affairs Research and Practice, 48(4), 1-30. doi:10.2202/1949-6605.6198

McGoldrick, B., Watts, J.S, \& Economou, K. (2015). U.S. postsecondary faculty in 2015. Retrieved from http://postsecondary.gatesfoundation.org/wp-content/uploads/2015/02/US-Postsecondary-Faculty-in2015.pdf 
Myers, R. (1990). Classical and modern regression with applications (2nd ed.). Boston, MA: Duxbury Press.

Pascarella, E. T. (1985). College environmental influences on learning and cognitive development: A critical review and synthesis. Higher Education: Handbook of Theory and Research, $1,1-61$.

Pascarella, E. T. (2001). Using student self-reported gains to estimate college impact: A cautionary tale. Journal of College Student Development, 42(5), 488-492.

Pascarella, E. T. (2006). How college affects students: Ten directions for future research. Journal of College Student Development, 47(5), 508-520. doi:10.1353/csd.2006.0060

Pascarella, E. T., Bohr, L., Nora, A., \& Terenzini, P. (1995). Cognitive effects of 2-year and 4-year colleges: New evidence. Educational Evaluation and Policy Analysis, 17(1), 83-96. doi:10.3102/01623737017001083

Pascarella, E. T., \& Terenzini, P. T. (1991). How college affects students: Findings and insights from twenty years of research. San Francisco, CA: Jossey-Bass.

Pascarella, E. T, \& Terenzini, P. T. (2005). How college affects students (Vol. 2): A third decade of research. San Francisco, CA: Jossey-Bass.

Pascarella, E. T., Wolniak, G. C., \& Pierson, C. T. (2003). Explaining student growth in college when you don't think you are. Journal of College Student Development, 44(1), 122-126. doi:10.1353/csd.2003.0007

Pedhazur, E. J. (1982). Multiple regression in behavioral research: Explanation and prediction. (2nd ed.). Orlando, FL: Harcourt Brace Jovanovich College Publishers.

Pike, G. R. (1996). Limitations of using students' self-reports of academic development as proxies for traditional achievement measures. Research in Higher Education, 37(1), 89-114. doi:10.1007/BF01680043

Raudenbush, S. W., \& Bryk, A. S. (2001). Hierarchical linear models: Applications and data analysis methods. Thousand Oaks, CA: Sage Publications.

Smeaton, A., \& Keogh, G. (1999). An analysis of the use of virtual delivery on undergraduate lectures. Computers and Education, 32(1), 83-94. doi:10.1016/S0360-1315(98)00052-9

Sorcinelli, M. D., Austin, A. E., Eddy, P. L., \& Beach, A. L. (2006). Creating the future of faculty development: Learning from the past, understanding the present. Bolton, MA: Anker.

Tamim, R. M., Bernard, R. M., Borokhovski, E., Abrami, P. C., \& Schmid, R. F. (2011). What forty years of research says about the impact of technology on learning: A second-order meta-analysis and validation study. Review of Educational Research, 81(1), 4-28. doi:10.3102/0034654310393361

Taraban, R., \& Rynearson, K. (1998). Computer-based comprehension research in a content area. Journal of Developmental Education, 21(3), 10-18.

Tjaden, V., \& Martin, C. (1995). Learning effects of CAI on college students. Computers \& Education, 24(4), 271-277. doi: 10.1016/0360-1315(95)00031-G

U.S. Department of Education. (2006). A test of leadership, charting the future of U.S. higher education: A report of the commission appointed by Secretary of Education Margaret Spellings. Washington, DC: U.S. Department of Education.

U.S. Department of Education. Institute of Education Sciences, National Center for Education Statistics. (2008). Projections of education statistics to 2017 (NCES 2008-078). Retrieved November 1, 2013, from nces.ed.gov/pubs2008/2008078.pdf

Vygotsky, L. S. (1978). Mind in society: The development of higher mental processes. Cambridge, MA: Harvard University Press. 
Zhu, E., \& Kaplan, M (2014). Teaching with technology. In M. D. Svinicki \& M. J. McKeachie (Eds), McKeachie's teaching tips: Strategies, research, and theory for college and university teachers (pp. 232-264). Belmont, CA: Wadsworth.

\section{Biographies}

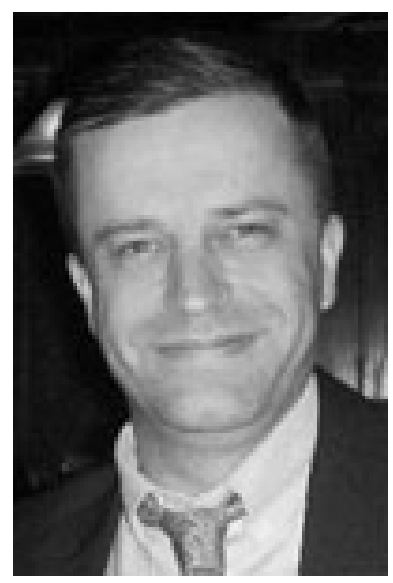

Chad Loes is Director of Student Outcomes Research and Professor of Criminal Justice at Mount Mercy University. He is a former Thomas R. Feld Endowed Chair for Teaching Excellence, and teaches a variety of courses including Research Design and Diversity and the Criminal Justice System. His research explores a wide array of topics such as cognitive development/critical thinking, effective instructional techniques, student persistence, missing data, and diversity-related issues. His work appears in a variety of outlets such as The Journal of Higher Education, New Directions for Institutional Research,Higher Education, Journal of the Scholarship of Teaching and Learning, and the International Journal for the Scholarship of Teaching \& Learning.

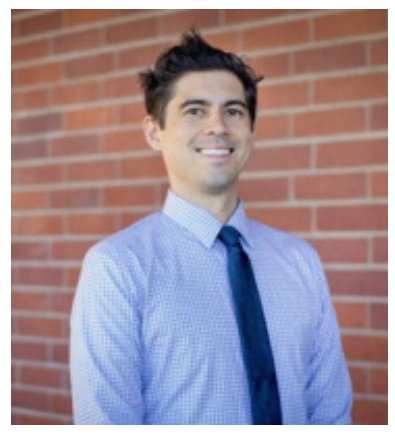

Kem Saichaie is Associate Director for the Center for Educational Effectiveness at the University of California, Davis. He leads the Learning and Teaching Support unit that works with faculty and teaching assistants to integrate learner-centered, evidence-based pedagogical practices into traditional, hybrid, and online classrooms. Saichaie has an active research agenda that focuses on pedagogical innovations, learning spaces, academic marketing, and the scholarship of teaching and learning. He is a co-author of the book: A guide to teaching in active learning classrooms: History, research, and practice. Saichaie has published in a number of venues including The Journal of Higher Education, International Journal for the Scholarship of Teaching and Learning, Medical Teacher, New Directions in Teaching and Learning (Learning Spaces volume), New Directions in Institutional Research, and EDUCAUSE's Seeking Evidence of Impact series. He earned a PhD Higher Education and Student Affairs from The University of Iowa in 2011. 